\title{
Ecrãnologia: a dimensão visual da experiência
}

\author{
Fabio La Rocca
}

\author{
Laboratoire d'Études Interdisciplinaires sur le Réel et les \\ Imaginaires Sociaux (LEIRIS), Université Paul Valéry \\ Montpellier 3, Montpellier, França \\ https://orcid.org/0000-0001-7635-5666
}

\begin{abstract}
A nossa existência social está cada vez mais contaminada pelas relações com as imagens e pela presença do ecrã. Da perspetiva da compreensão do espírito dos tempos, podemos, portanto, destacar a construção de uma visão do mundo expressa por imagens e ecrãs que formam uma dimensão particular da experiência. Como é que as imagens e ecrãs estruturam então o nosso imaginário social? Quais são as formas das experiências da vida quotidiana? Estas perguntas levam-nos a refletir sobre uma existência em que o ver se torna uma ação central do mundo social atual através da perspetiva da screenologia como efeito e condição de um ambiente tecnológico e mediático em que os ecrãs devem ser pensados como superfícies habitadas.
\end{abstract}

Palavras-chave: ecrã, imaginário, imagens, cultura visual, mediologia

\section{Screenology: the visual dimensions of experience}

\begin{abstract}
Our social existence is increasingly contaminated by relations with images and the presence of the screen. From the perspective of understanding the spirit of the times, we can therefore highlight the construction of a vision of the world expressed by images and screens that form a particular dimension of the experience. How then do images and screens structure our social imaginary? What are the forms of the experiences of everyday life? Questions that will lead us to reflect on an existence in which seeing becomes a central action of the current social world through the perspective of screenology as an effect and condition of a technological and media environment in which screens must be thought of as inhabited surfaces.
\end{abstract}

Keywords: screen, imaginary, images, visual culture, mediology

Submetido: 17/03/2021 | Revisto: 02/04/2021 | Aceite: 14/04/2021 | Publicado: 02/06/2021

“Portanto, mais uma vez: não pense, mas veja!"

(Wittgenstein, 1984, p. 277)

A nossa época é cada vez mais marcada pela importância da imagem que caracteriza uma dimensão visual do mundo social. O panorama cultural atual distingue-se por um ambiente visual que nos rodeia numa época que, segundo Gillian Rose (2007), é definida como "oculocêntrica", em que predomina a centralidade da visão como um efeito de contaminação do corpo social. A experiência do mundo, a nossa forma de estar no mundo, é assim a de uma incorporação visual onde a forma e o ato de "ver" representam tanto uma démarche de conhecimento como uma forma interativa com o mundo. A centralidade do olho - é de salientar que esta centralidade não anula os outros sentidos no ato de conhecer e de interagir - mostra-nos como estamos cada vez mais numa ação de procura 
visual dos elementos do nosso mundo. Referimo-nos à atenção visual, na qual o ato de ver é uma ação central e na qual o olhar, seguindo aqui a análise de Anne Sauvageot (1994), representa um produto do social e também um produtor de saber. Neste caso, falaremos de uma démarche de "saber ver" o mundo através dos processos de visualização, o que significa dizer e construir uma narrativa do mundo, isto é, produzir uma Weltanschauung: ou seja, uma visão do mundo baseada no ato de visualização para determinar os fragmentos da nossa realidade. Nesta perspetiva, será necessário adotar uma postura epistemológica compreensiva que enfatize uma pluri-perspetiva da qual os Estudos de Cultura Visual deveriam nutrir-se com o fim de propor um conhecimento deste mundo sócio-visual.

Além disso, a cultura visual, colocando no centro da análise a dinâmica das imagens como modalidade percetiva e comunicativa e também de construção social da realidade, opera de acordo com a nossa perspetiva uma atitude de "mostração", isto é, uma ação capaz de produzir sentido e conhecimento e de estabelecer uma visão estética-sensitiva do mundo da vida quotidiana.

Heuristicamente, o sensível como faculdade de "sentir" e a teoria sensitiva que enfatiza os sentidos, mostram os efeitos de um processo de visualização do mundo e do carácter visual da experiência, que devemos considerar também como uma espécie de espírito científico e de revolução epistemológica que reabilita, seguindo a ótica de Gilbert Durand (1960), o papel das imagens e do imaginário no processo de conhecimento. Ao enfatizar a importância da imagem e o processo percetivo de ver e de saber, existe uma relação indicial com a realidade. A profusão de imagens e dos dispositivos visuais transforma e afeta o corpo social. Na direção de uma sensibilidade sociológica que nos permite apresentar o mundo em que vivemos, o ato de mostrar designa o caminho, a indicação e o fazer ver, gerando assim aquilo a que se pode chamar uma "instância de mostração" da imagem que representa uma gravação daquilo a que os nossos olhos prestam atenção.

É necessário mergulhar na dimensão visual do mundo, enfatizando a intensificação da solicitação visual, onde a imagem deve ser pensada numa forma "climatológica" da vida quotidiana, uma vez que participa na constituição das esferas sociais e representa uma tipologia epistemológica do conhecimento. Uma sensibilidade fenomenológica está também em jogo nesta profusão de imagens, uma sensibilidade que relaciona a nossa consciência com as coisas do mundo, desenvolvendo, numa perspetiva husserliana (Husserl, 1950), uma "visão das essências". O nosso olhar é então dirigido para estas várias "essências" a fim de ilustrar aspetos socioculturais, em que a imagem é uma condição de possibilidade, um espaço no qual, seguindo o pensamento de Walter Benjamin (1936/2003), a nossa experiência é consumida.

De um ponto de vista paradigmático, no que diz respeito ao nosso espírito do tempo contemporâneo (zeitgeist), há a necessidade de mudar a estrutura conceptual com que olhamos para o mundo. Uma forma de ajustamento com o espírito do tempo é necessária para indicar as direções para as quais faz falta orientar o olhar, um modelo a partir do qual podemos estabelecer uma elaboração teórica de uma visão do mundo. Se o angelus novus de Benjamin (1936/2003), relativamente ao tempo, tinha o seu olhar orientado para trás, para o passado, hoje esse olhar está mergulhado no presente, numa forma de atenção da ação em adaptar o olho e a mente a um novo modo de ver que deve, portanto, ter em conta a evolução técnica e dos instrumentos da visão.

Neste tipo de discurso, que se baseia na evolução das formas de ver e de pensar, podemos concentrar-nos nas estruturas visuais contemporâneas em que a evolução da técnica, do ponto de vista das mudanças sociais, dos aspetos culturais e dos dispositivos, favorece e adapta os instrumentos do ver. As formas comunicativas, os dispositivos que nos permitem ver e nos fazem ver são então essenciais, uma vez que a perceção do vivido nunca é independente da estrutura técnica e dos instrumentos que nos possibilitam ampliar a apreensão do real. A técnica, neste sentido, constrói e produz o real e é assim possível destacar as várias alterações visuais que influenciam a nossa modalidade de visão através de uma lógica de sucessão mediológica, na qual a linguagem visual tem uma prevalência sócio-estética cada vez maior. 
Num tipo de caminho, o do imaginário social, podemos ilustrar as diferentes sucessões tecnomediáticas que têm impacto na nossa esfera social e nos canalizam para uma trans-imersão num contexto cada vez mais visual que também influencia o conhecimento. Se na era moderna o conhecimento era transmitido através da linguagem verbal, na nossa era contemporânea as imagens estão a tornar-se cada vez mais a forma cultural predominante, gerando a conceção de um mundo como imagem. Além disso, recordemos que a crise das grandes narrativas evidenciada por Jean-François Lyotard (1979) coincide com a transição de uma cultura textual para uma cultura visual.

De um ponto de vista histórico, temos testemunhado uma predominância do visual com as múltiplas transmutações da fotografia e do cinema como artes de fazer ver e de mostrar, tendo uma atenção visual sobre o mundo. Assim, o aparecimento de uma famosa iconic turn, assim denominada por Gottfried Boehm (1994) no seu questionamento: Was ist ein bild? (O que é uma imagem?) e depois desenvolvida por W. J. T. Mitchell (1994) com a sua pictural turn - que deve ser entendida não como uma simples afirmação de uma presença maciça de imagens, mas antes pela sua importância em designar o poder das imagens como produtoras de sentido, anunciando assim uma viragem hermenêutica, ou seja, um saber das imagens que deve ser concebido também na direção de uma tomada em consideração do advento das novas tecnologias. A iconic turn de Boehm apontava para que a imagem fosse um ato fundador de sentido (Stiegler, 2008); estamos perante uma mudança de paradigma que define um certo logos icónico, que encontramos na ação de ver e na lógica das imagens a ser entendida como "a lógica da mostração" (Boehm, 2010, p. 35). Assim, a iconic turn coloca-nos numa reformulação do estatuto da imagem e numa mudança paradigmática que acentua o valor dos estudos visuais contra aquilo a que Mitchell (1994) chamou "o imperialismo da textualidade", procurando assim instaurar um pensamento com e sobre as imagens.

Evidentemente, isto não significa, na nossa opinião, um confronto binário linguagem/imagem ou ainda a anulação de uma em relação à outra. Seria demasiado vasto e amplo discursar sobre o discurso, contentar-nos-emos em salientar que a imagem é uma linguagem que exprime o sentido do real e esta "viragem" mostra a evolução da imagem no mundo social, que hoje em dia tem que ser compreendida conjuntamente com a perspetivação da influência da mudança tecnológica que define a alfabetização visual, de modo que poderíamos falar de uma espécie iconic turn techno.

Portanto, isto não significa apagar a linguagem, mas considerar a importância do visual como texto e como linguagem que se fundem e se articulam através de novas formas digitais que nos permitem, permanecendo na lógica do pensamento de Boehm (1994), expressar novos significados. Se, por um lado, estamos a viver um caos visual ou mesmo uma perturbação visual ou ainda uma fase de choque visual que invade a nossa vida quotidiana, devemos, no entanto, considerar as imagens numa relação dinâmica e vitalista, no sentido em que estas imagens, como o observa Mitchel (1994), são sujeitos vivos que interagem com o indivíduo/espectador. A proliferação de imagens na era da sua reprodutibilidade tecnológica (La Rocca, 2015) deve também ser entendida como uma das formas possíveis de ter acesso ao mundo. Um mundo feito de imagens e um mundo em imagens, ou ainda um mundo como imagem que nos mostra que a imagem constitui um elemento característico na construção social da realidade. Em cada época a imagem tem uma especificidade num contexto cultural e com as suas próprias formas expressivas, e para além de ser um meio de transmissão deve também ser pensada como um meio que nos permite compreender e conhecer o mundo. Estamos numa lógica de mostração e de apresentação visual em que os vários instrumentos de visualização representam um fundamento a partir do qual a realidade social é construída. Fazendo eco da análise histórica de Peter Berger e Thomas Luckmann (1966), podemos mostrar que a imagem participa neste processo e através dela percebemos a realidade, ou seja, o mundo da vida quotidiana na sua presença imanente que partilhamos com os outros. É nas banalidades da vida quotidiana que devemos mergulhar para realçar o poder da imagem e do imaginário como formas estruturantes que cristalizam este vivido quotidiano. Cristalização como uma visão de um mundo que representa o espelho do vivido, onde é possível observar uma Bildung visual como processo informativo e formativo a partir do qual as imagens desempenham um papel edificador de religação social com os seus múltiplos significados verificáveis na sua presença que mediatiza as interações e as interconexões. A presença da imagem não é apenas um espelho do 
mundo, mas também uma edificação deste mundo em que os indivíduos dão sentido às suas ações através de imagens que devemos ser capazes de interpretar e identificar com significados simbólicos, enquanto produzidos numa atividade social e tendo um impacto tanto ontológico como fenomenológico sobre a realidade.

As imagens, há que recordá-lo, não são cópias fiéis do real, mas são o real figurado e apresentado ao qual queremos dar um sentido através das configurações das trocas recíprocas que hoje em dia estão cada vez mais atualizadas por meio da prática da imagem partilhada (Gunthert, 2015) por meio das tecnologias.

O ambiente tecno-mediático deve ser considerado como uma forma de influência sobre o vivido, onde podemos observar a preponderância do desenvolvimento da relação interfacial existencial entre os indivíduos, evidenciando claramente uma característica do uso dos dispositivos e o seu condicionamento do mundo social. Cria-se então um percurso do imaginário que engloba a sucessão tecno-mediática que se origina nas formas do vivido da nossa contemporaneidade contaminada por objetos nómadas, pelo imediatismo, por mensagens emotivas, pela circulação de emoções visuais nos fluxos comunicacionais, pela ecrãnologia da existência e pela presença por meio das interfaces digitais. Este conjunto, na nossa perspetiva, gera um tipo de Dasein tecnológico por meio do qual habitamos o nosso mundo através das plataformas comunicacionais. Trata-se de uma situação pós-orgânica na qual o ser se funde com a técnica ao criar um hibridismo que podemos destacar através de uma penetração tecno-simbólica ao modificar os aspetos sensoriais. Pensemos, por exemplo, nas várias mutações no quotidiano, tais como a presença "ecrãnológica", o smartphone, a hiper-conectividade, a lógica ubimediática e aquilo a que chamamos o homem-fluxo. Estes são alguns elementos que nos parecem relevantes para expressar a época em que nos encontramos e onde existe a possibilidade de observar a passagem da centralidade mono-psíquica para a personalidade fluxo-esquizóide, decretando assim a morte do sujeito cartesiano e a atual presença híbrida do homem simbiótico.

Do ponto de vista do processo de construção da realidade social e das identidades e das consequentes "afinidades conectivas" (Susca, 2016), é necessário ter em conta esta fusão híbrida do real com o habitar digital e as suas múltiplas janelas que, segundo Sherry Turkle (1996), na vida quotidiana, através de interfaces, se tornam metáforas para pensar o "eu" como um sistema múltiplo. Na sequência da análise do Turkle (1996), parece legítimo questionar se vivemos sobre o ecrã ou no ecrã. Mas também podemos acrescentar através do ecrã. Isto torna manifesta a forma como o indivíduo se encontra numa situação de foto-presença, vídeo-presença: isto é, uma visualização percetiva do ser e dos seus modos de habitar. A visualização é, portanto, uma instantaneidade do vivido, um sentimento ontofânico como uma nova forma de habitar o mundo, de se sentir no mundo (Vial, 2013, p. 152). Recordemos que a ontofania é uma forma de aparecimento do ser e algo que se nos mostra e que encontramos na análise de Mircea Eliade (1965) sobre os mitos e o sagrado.

Assim, na era da imagem tecnológica e da presença "ecrãnológica", podemos notar um tipo de ontofania que representa ao mesmo tempo uma forma de narração através das próteses tecnológicas, como o smartphone e a sucessiva explosão do visual. Neste sentido, teremos de nos perguntar qual é a nossa relação com o dispositivo dos ecrãs e de que forma é que estes ecrãs modificam as nossas relações? Temos de pensar os ecrãs como superfícies de projeção da nossa existência através das quais se origina uma manifestação do ser e da aparência. Uma projeção acompanhada pela identificação, isto é, um processo enfático de fenómenos expressivos que se manifestam na relação com o outro, uma relação que, neste tipo de situação, é mediada pelo ecrã. Olhar para o real através de ecrãs coloca-nos na condição de considerar uma modalidade existencial onde a intersubjetividade, usando o pensamento de Heidegger (1927), na sua obra Sein und Zeit (Ser e tempo), é o domínio do "estar-com" os outros. Além disso, seguindo a lógica heideggeriana, sabemos que o estar-cá é um-estar-no-mundo e, por isso, na perspetiva da ecrãnologia, o ecrã representa uma superfície habitada que nos outorga um estar-cá; uma superfície, aliás, considerada por Giuliana Bruno (2014) como uma configuração material das 
relações entre sujeitos e objetos e que é vista como um meio, uma atmosfera de projeção. É nesta ótica de projeção que podemos ilustrar a ecrãnologia proposta por Erkki Huhtamo (2004) através da sua proposta da "arqueologia dos media" que questiona a natureza dos ecrãs como superfícies e suportes para o aparecimento dos fenómenos visuais. Na ótica de Huhtamo (2004), o ecrã é definido como superfície de informação e a cultura da imagem se encontra então numa proposta de novas formas de visão de um ponto de vista sócio-cultural da experiência. Desse jeito, os ecrãs são superfícies ambientais que também conectam as várias espacialidades e os lugares onde estão presentes, reconfigurando, assim, a nossa prática sócio-espacial. Além disso, o semiólogo e perito em meios de comunicação Francesco Casetti (2014), no seu questionamento Che cosa è uno schermo oggi?, coloca em perspetiva o facto de, na nossa existência quotidiana, estarmos numa relação crescente com ecrãs que modifica a própria natureza do ecrã, ao tornar-se uma forma de display que deve ser entendida como um lugar onde as imagens flutuam. A função do ecrã, para Casetti (2014), deve ser entendida como um ponto de passagem para imagens que circulam no nosso espaço social, imagens que, graças aos ecrãs, estão então disponíveis em todo o lugar. O ecrã-display de Casetti (2014) é, portanto, uma nova forma ecrãnica que torna as imagens presentes, ao colocá-las à nossa frente para as utilizar como imagens a circular.

Neste contexto, podemos orientar o olhar para as relações intermediais e as formas culturais, ao considerar os ecrãs também como uma forma narrativa. Na dinâmica da projeção/identificação, observamos no sinal de uma evolução tecnológica a passagem do indivíduo para o dividu, com as suas máscaras e identidades múltiplas e efémeras. Na contemporaneidade tecnológica tudo é divisível, tudo é móvel e tudo é fluxo. E é na mobilidade perene, na aceleração dos percursos, que podemos ver a evidência da presença ecrãnica do vivido através daquilo que podemos definir como uma "alterologia ecrãnica", onde o ecrã é o meio, o ambiente que nos coloca, em qualquer caso, em contacto com o real que torna o vivido visível em todas as suas formas. Ao colocarmo-nos na dinâmica do pensamento fenomenológico de Maurice Merleau-Ponty (1960), em relação aos ecrãs, podemos notar "sinais do visível", participando na estrutura imaginária do real que se torna visível através da mediação ecrãnológica. Através dos ecrãs, atualiza-se a lógica da revelação do vivido, ou do pôr em linha da vida quotidiana, onde as várias redes sociais representam a sua expressão mais aparente. Se o quotidiano é cada vez mais vivido em frente e através de ecrãs nas suas múltiplas formas e nas diversas espacialidades existenciais, devemos então pensar estes ecrãs não como simples dispositivos tecnológicos, mas como dispositivos óticos ambientais que influenciam a mente e as emoções. São, portanto, dispositivos ontológicos que caracterizam o nosso estar-no-mundo e que oferecem a possibilidade interativa com a qual o "eu" se realiza por meio dos "outros". E aqui podemos pensar no efeito de espelho ou ainda no looking glass self do sociólogo americano Charles Horton Cooley (1902), um "eu" reflexo que podemos observar, na nossa ótica, também através de ecrãs. Se os outros são o espelho de mim próprio, então do ponto de vista da partilha de imagens de nós próprios e do nosso próprio vivido, realça-se esta vontade de fusão, de pôr a nu a nossa própria existência, que se externaliza nos processos mediáticos da participação em comum. Nisto podemos compreender, por exemplo, a serialidade das imagens de nós próprios na captação instagramada do nosso quotidiano, uma espécie de "dramaturgia do quotidiano", usando aqui uma expressão goffmaniana (Goffman, 1959), que destaca este efeito de encenação de si próprio para ser e aparecer.

No permanente intercâmbio de rios de imagens de nós e do ambiente que nos rodeia, somos confrontados com uma transformação da perceção do mundo, onde a "fluidez" é a essência desta dimensão de partilha na qual a prática das imagens se torna, como o mostra André Gunthert (2015), uma prática "conversacional". Os vários fragmentos de imagens expostos e partilhados através dos ecrãs constituem um conjunto daquilo que se pode chamar um "puzzle da imaginação" contemporâneo e orientam o olhar para uma atenção a esta fluidez existencial na qual - sem qualquer juízo moral - também se organiza um tipo de olhar direcional para as formas do vivido que estão expostas na paisagem rizómica da rede digital, ao desenvolver e reforçar a construção social da realidade. Neste cenário, fica reforçada a ideia de presença no mundo que passa pela visualização. Com efeito, a perceção do vivido e da presença, o estar-no-mundo não são independentes da situação tecnológica e dos instrumentos que nos permitem alargar o real. Além 
disso, recordemos como Roland Barthes (1980), na sua obra La chambre claire. Note sur la photographie, mostrou que a fotografia garante a existência do real e certifica a presença. Assim, a dimensão atual de fluidez visual parece reforçar esta presença, que não deve ser pensada apenas na simples (e também patética) crítica pisco-patológica que mostra os efeitos nocivos desta epidemia de imagens. É nesta atmosfera de pregnância do visual, em que estamos inseridos, que se realiza a exposição do vivido filtrada pelos ecrãs, onde se exibem os próprios retratos, as máscaras e as facetas dos seres. Somos confrontados com a ideia ilustrada por Andrea Somaini (2013) de que o meio de perceção (de origem Benjaminiana, é preciso salientá-lo) é um meio sensorial que condiciona o que está a ser vivido.

Neste discurso de uma extensão sensorial, a cultura da selfie, por exemplo, pode ser pensada como um movimento do ser que se espacializa e se duplica na ubiquidade da sua presença. Se, de facto, Esse est percipi, de acordo com a famosa fórmula filosófica do teólogo irlandês Georges Berkeley (1710/1920, p. 3), isto é, "ser é ser percebido", poderíamos então relacionar esta formulação com a técnica da selfie, da visão do eu para ser percebido na complementaridade da presença que circula nos territórios existenciais digitais. Um ser-no-mundo através do qual o ecrã se projeta no interior do mundo e nos permite sermos vistos do exterior e visualizar aspetos da nossa experiência vivida. A selfie, como efeito "ecrãnológico" do ser, é uma tendência para ser visível de uma forma perene, um retorno ao eu em que este mesmo "eu" se concebe através do outro que partilha os instantes e participa na fluidez visual do ser. O ecrã é então uma revolução fenomenológica que põe em ação um sistema múltiplo, no qual o "eu" deve ser pensado como uma acumulação de várias presenças instantâneas que dá origem a uma multiplicidade de identidades. Estamos então numa ótica de copresença e de um viver com: um viver com e através dos ecrãs, que representam "noções discursivas" (Huhtamo, 2004, p. 33) e permitem a narração do vivido que se atualiza por meio da capacidade de display que, no fluxo da vida quotidiana, impregna o processo de visualização. Poderíamos reformular o famoso cogito ergo sum de Descartes (1637/1894) com a passagem "sou visto, logo sou" ou "vejo, logo sou": uma passagem que ilustra a modalidade com a qual os fragmentos da vida quotidiana são exibidos nas paredes digitais (pensamos no Facebook, por exemplo) ou "instantaneizados" no fluxo de fotografias difusas (como no caso do Instagram) imortalizadas nas situações de representação do "eu" (ou seja, a selfie). Esta situação percetiva não diz apenas respeito a um acontecimento histórico-social atual, mas coincide também com a revelação de uma nova experiência fenomenológica do mundo, da modalidade através da qual a existência é e aparece. É também o sinal de uma extensão sensorial e percetiva do nosso olhar que muda de natureza através da solicitação e da estimulação do captar e do capturar os instantes quotidianos imortalizados visualmente graças à facilidade de acesso tecno-digital ao processo de visualização. Photo ergo sum ou Video ergo sum são uma transmutação do vivido, mostrando de que maneira a propagação dos aparelhos e dos ecrãs de visão aumenta o pôr em forma do quotidiano, onde podemos ver uma produção das formas estéticas (no sentido de uma perceção partilhada) no fluxo conectivo que caracteriza o espírito contemporâneo. A visão é ampliada, aumentada e a experiência in visu é vivida na modalidade percetiva oferecida pela mediatização "ecrãnológica" tecno-digital. Fotografar e filmar a vida quotidiana com o smartphone, que deve ser pensado como uma extensão sensorial que determina uma espécie de "terceiro olho" - que nos remete para a ideia de "cine-olho" em The man with a movie camera, de Dziga Vertov (1923) - um ato ao qual acrescentamos a ação de partilhar as instantaneidades vividas e a troca de experiências a fim de criar ligações tecno-simbólicas, torna-se agora um processo normal para captar o mundo em imagens. Um mundo de hiperestimulação visual que gera hiper-visibilidade, onde o corpo social se mostra continuamente. Diariamente, comunicamos aos outros facetas de nós próprios através de uma tipologia de face a face "ecrãnológica", que deve ser entendida como uma relação constante com a imagem e com a partilha, representando assim a visibilidade do corpo social. Isto produz uma espécie de carnavalização comunicacional, na qual a selfie, no nosso entender, indica a tendência mais banal e fundadora do desejo de ser visto; pode ser concebida e interpretada como um objeto para compreender as mutações das formas comunicativas, um meio e uma prática para enviar mensagens visuais a várias comunidades e para intensificar as ligações ou uma sacralidade afetiva, um modo de expressão de situações emocionais e da nossa própria existência sócioespacial. As interfaces ecrãnológicas, estéticas e sensíveis permitem esta profusão e circulação de 
emoções e, neste panorama, a prática visual da fotografia digital e o universo cultural selfieInstagram do universo cultural outorgam a visualização da existência, concedendo a externalização do momento presente da manifestação identitária. A ecrãnologia do vivido, através dos múltiplos atos que gera, leva a uma dilatação do mundo que deve ser entendida como uma das formas comunicativas contemporâneas, nas quais é ativado o êxtase da partilha e da conectividade emocional. Trata-se de experimentar o mundo e de viver o presente na sua imanência instantânea, de mergulhar no ambiente experiencial em que apropriar-se o mundo significa também aderir a esta gestualidade de captar e de capturar através dos ecrãs e dos estilos de visualização digital, que se tornaram um hábito do vivido.

Se cada época tem as suas convenções estilísticas, podemos compreender como as técnicas de visão são fruto de uma ação percetiva aumentada; e compreender também, a partir da teoria de Joshua Meyrowirtz (1985), que a modificação da estrutura da situação social, as transformações de uma situação envolvem ao mesmo tempo a modificação do papel dos indivíduos e a forma como os instrumentos técnicos de comunicação e de visualização mudam o nosso modo de habitar e de estar presente num lugar. Estamos confrontados com uma "geografia situacional" (Meyrowitz, 1985, p. 373) que pode ser interpretada hoje em dia através da mobilidade difusa. A nossa atitude atual de estarmos sempre disponíveis para a ação de ver e de mostrar pode também ser entendida como um sintoma de uma ontologia do ser e da instrumentação técnica que modifica os traços existenciais e percetivos. Torna-se claro, então, que a contaminação ecrãnológica significa também a contaminação do real, onde é possível apreender e ver esse real através das imagens projetadas e difundidas pelos nossos ecrãs. Estamos imersos numa cultura comunicacional digital que mostra que o digital não é uma substância morta, mas sim um espaço habitado, um ambiente dotado de um conjunto de espaços conectivos. A experiência do mundo é assim influenciada por este conjunto e não podemos negligenciar a contribuição do digital, das interfaces tecnológicas na constituição do vivido. A troca perpétua de fotografias e de vídeos, o momento das mensagens visuais, o instant messaging visual, o ludismo hipermediático, a visão nomádica pelo intermédio dos aparelhos sensoriais, as trocas emoticon-emocionais e o divertimento dos gifs: tudo isto forma uma composição de ações que alimentam a visão e a perceção de detalhes e de fragmentos do ser-nomundo. Um ser-no-mundo que se torna cada vez mais reconhecido visualmente ao dar a todas essas ações uma conotação sociocultural bem definida com uma relevância daquilo que é o agir comunicacional contemporâneo. Um agir que tem lugar e substância na sua componente fenomenológica do "mundo da vida", para o exprimir à maneira de Alfred Schütz (1987), da experiência do quotidiano, portanto, de onde se observam as atitudes dos indivíduos que se manifestam em ações simbólicas e através dos seus signos comunicacionais singulares, a fim de organizar este mundo de ação quotidiana.

No processo de conhecimento é necessário criar uma sinergia de aclimatação, ou seja, um modo de desvendar as raízes do que se vive no hic et nunc da atmosfera situacional, a fim de reformular um sentido do real através da experiência ecrãnológica do vivido. A ecrãnologia que propomos deve ser considerada como um novo naturalismo que condiciona os modos de acesso ao universo social. $\mathrm{O}$ imaginário ecrãnológico - poderíamos, por exemplo, discursar sobre a fenomenologia da série Black Mirror (Brooker, 2011-2014), que é um bom retrato do nosso mundo ou uma Weltan schauung, enquanto representação sensível do mundo, uma nova visão que produz uma experiência sensorial - é uma destas condições de possibilidade para a compreensão da natureza humana que nos empurra para uma conexão entre o real, o imaginário e o digital para facilitar a ilustração dos fragmentos do mundo que vivenciamos.

\section{Tradução: Jean-Martin Rabot}

\section{Nota biográfica}

Fabio La Rocca é sociólogo, Professor Associado na Universidade Paul-Valéry Montpellier 3, onde é membro do Laboratório de Estudos Interdisciplinares sobre Realidade e Imaginários Sociais 
(LEIRIS). Membro do grupo de investigação "Comunicação, Arte e Cidade", Programa de PósGraduação em Comunicação, Universidade do Estado do Rio de Janeiro (Brasil) e do Grupo Kinepolitcon (Pontifícia Universidade Católica do Rio Grande do Sul, Brasil). Tem experiência no campo da Sociologia, com ênfase nos temas das cidades e ambientes urbanos, sociologia visual, sociologia do imaginário, cultura, comunicação e meios de comunicação. É autor do livro La ville dans tous ses états (edições CNRS, 2013, Cidade em todas as suas formas, Sulina, 2018) e de vários artigos e capítulos de livros sobre a cidade, sociologia visual, tecnologia, cultura.

\section{ORCID: https://orcid.org/0000-0001-7635-5666}

\section{Email: fabio.la-rocca@univ-montp3.fr}

Morada: Department of sociology, LEIRIS, University Paul-Valéry Montpellier 3 Route de Mende, 34199 Montpellier Cedex 5, França

\section{Referências}

Barthes, R. (1980). La chambre claire. Note sur la photographie. Seuil.

Benjamin, W. (1936/2003). L'œuvre d'art à l'époque de sa reproductibilité technique. Allia.

Berger, P., \& Luckmann, T. (1966). The social construction of reality. A treatise in the sociology of knowledge. Méridiens-Klincksieck.

Berkeley, G. (1710/1920). Les principes de la connaissance humaine. Librairie Armand Colin.

Boehm, G. (1994). Il ritorno delle immagini. In A. Pinotti \& A. Somaini (Eds.), Teoria delle immagini. Il dibattitocontemporâneo (pp. 39-72). Cortina.

Boehm, G. (2010). Ce qui se montre. De la différence iconique. In E. Alloa (Ed.), Penserl'image (pp. 27-47). Presses du réel.

Brooker, C. (Executive Producer) (2011-2014). Black Mirror (TV Series). Seppotron/House of Tomorrow.

Bruno, G. (2014). Surface. Matters of aesthetics, materiality and media. The University of Chicago Press.

Casetti, F. (2014). Che cosa è uno schermo, oggi? Rivistadiestetica, 55, 103-121.

https://doi.org/10.4000/estetica.969

Cooley, C. (1902). Human nature and the social order. Routledge.

Descartes, R. (1637/1894). Discours de la méthode. Librairie de la Bibliothèque Nationale.

Durand, G. (1960). Les Structures anthropologiques de l'imaginaire: Introduction à

l'archétypologie générale. P.U.F.

Eliade, M. (1965). Le sacré et le profane. Gallimard.

Goffman, E. (1959). The presentation of self in everyday life. Anchor Book.

Gunthert A. (2015). L’image partagée. La photographie numérique. Textuel. 
Heidegger, M. (1927). Sein und Zeit. Fratelli Bocca.

Huhtamo, E. (2004). Elements of screenology: Toward an archaeology of the screen. Iconics, 7, 31-82.

Husserl, E. (1950). Idées directrices pour une phénoménologie. Gallimard.

La Rocca, F. (2015). La sociologie visuelle à l'époque de la reproductibilité technologique de l'image. Iconocrazia, 7, 30-39.

Lyotard, J. (1979). La condition postmoderne. Rapport sur le savoir. Minuit.

Merleau-Ponty, M. (1960). L'œiletl'esprit. Gallimard.

Meyrowitz, J. (1985). No sense of place. The impact of the electronic media on social behavior. Oxford University Press.

Mitchell, W. (1994). Picture theory: Essays on verbal and visual representation. University of Chicago Press.

Rose, G. (2007). Visual methodologies. An introduction to the interpretation of visual materials. Sage.

Sauvageot, A. (1994). Voirs et savoirs: Esquisse d'une sociologie du regard. PUF.

Schütz, A. (1987). Le chercheur et le quotidien. Phénoménologie des sciences sociales. Méridiens Klincksieck.

Somaini, A. (2013). L'oggetto più importante per l'estetica. Benjamin, il cinema e il Medium della percezione. Fata Morgana, (20), 117-146.

Stiegler, B. (2008). Iconic Turn et réflecion sociétale. Trivium, 1, 1-7.

https://doi.org/10.4000/trivium.308

Susca, V. (2016). Les affinités connectives. Cerf.

Turkle, S. (1996). Life on the screen: Identity in the age of the internet. Simon \& Schuster.

Vertov, Z. (1923). Kinoks-Révolution. LEF, (3).

Vial, S. (2013). L'être et l'écran. PUF.

Wittgenstein, L. (1984). Philosophische Untersuchungen. Werkausgabe.

Este trabalho está licenciado com uma Licença Creative Commons - Atribuição 4.0 Internacional . 